\title{
SCIENTIFIC MOBILITY INDICATORS IN PRACTICE: INTERNATIONAL MOBILITY PROFILES AT THE COUNTRY LEVEL
}

\section{Indicadores de movilidad científica en acción: perfiles de movilidad internacional a nivel de país}

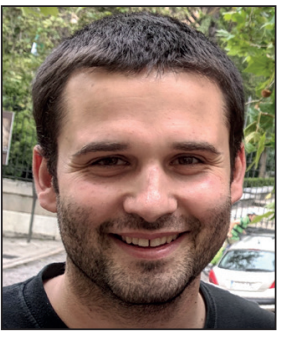

Nicolás Robinson-García is a postdoctoral researcher at the School of Public Policy from the Georgia Institute of Technology in the United States. He holds a PhD in Social Sciences from the University of Granada (Spain). He is interested in the development of quantitative methods to analyze scientific mobility flows as well as the analysis of new data sources and methods to trace societal engagement of researchers.

http://orcid.org/0000-0002-0585-7359

School of Public Policy. Georgia Institute of Technology North Avenue, Atlanta, EUA elrobinster@gmail.com

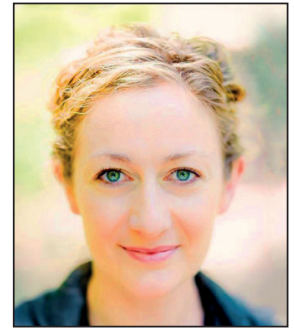

Cassidy R. Sugimoto is an associate professor of Informatics at the School of Informatics, Computing, and Engineering at Indiana University Bloomington. She conducts research within the domain of scholarly communication and scientometrics. She has published more than 70 journal articles on this topic. Her work has been presented at numerous conferences and has received research funding from the National Science Foundation and the Sloan Foundation, among other agencies. She is president of the International Society for Scientometrics and Informetrics and a visiting professor at CWTS, Leiden University.

https://orcid.org/0000-0001-8608-3203

School of Informatics and Computing Indiana University Bloomington, USA sugimoto@indiana.edu

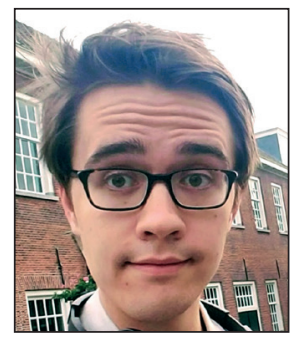

Dakota Murray is a PhD student at Indiana University Bloomington studying Informatics under the Computing, Culture, and Society Track. His research interests aim at better understanding the structure of the global enterprise of science and advocate for positive change to create a more equitable scientific ecosystem. He is advised by and works as a research assistant for Dr. Cassidy Sugimoto. He has been funded by the Eager grant sponsored by the NSF, and the IDEASc fellowship program sponsored by IMLS.

https://orcid.org/0000-0002-7119-0169

School of Informatics and Computing Indiana University Bloomington, USA dakota.s.murray@gmail.com

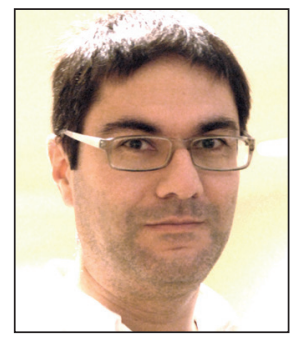

Alfredo Yegros-Yegros is a researcher at the Centre for Science and Technology Studies (CWTS) of Leiden University in The Netherlands. His research revolves around quantitative studies of science and technology. More specifically, the analysis of public-private research interactions and knowledge flows, the study of science-technology linkages, and the study of methods potentially able to capture societal impact of scientific research are some of his research interests.

https://orcid.org/0000-0002-0544-7878

Centre for Science and Technology Studies (CWTS) Leiden University, The Netherlands a.yegros@cwts.leidenuniv.nl 


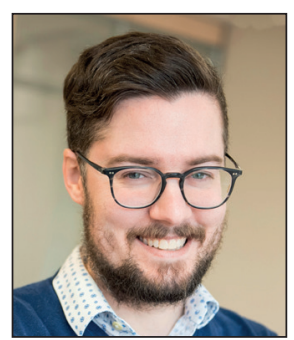

Vincent Larivière is associate professor of information science at the École de bibliothéconomie et des sciences de I>information, l'Université de Montréal, where he teaches research methods and bibliometrics. He is also the scientific director of the Érudit journal platform, associate scientific director of the Observatoire des sciences et des technologies and a regular member of the Centre interuniversitaire de recherche sur la science et la technologie. He is also a visiting researcher at CWTS, Leiden University. https://orcid.org/0000-0002-2733-0689

École de bibliothéconomie et des sciences de l'information Université de Montréal, Canada vincent.lariviere@umontreal.ca

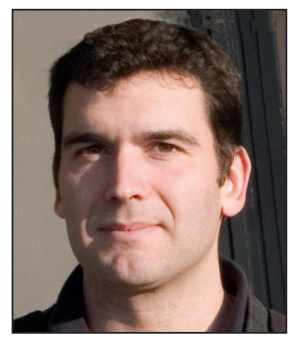

Rodrigo Costas is a senior researcher at the Centre for Science and Technology Studies (CWTS) at Leiden University, The Netherlands. He is also an extraordinary associate professor at the Centre for Research on Evaluation, Science and Technology (Crest) of Stellenbosch University, South Africa. He holds a PhD in Library and Information Science from CSIC in Spain. His areas of expertise include the fields of information science, scientometrics, and social media metrics. At CWTS he leads the research line in 'altmetrics', focused on developing new theoretical and analytical approaches to study the interactions between social media and science.

http://orcid.org/0000-0002-7465-6462

Centre for Science and Technology Studies (CWTS) Leiden University, The Netherlands.

DST-NRF Centre of Excellence in Scientometrics and Science, Technology and Innovation Policy Stellenbosch University, South Africa rcostas@cwts.leidenuniv.nl

\begin{abstract}
This paper presents and describes the methodological opportunities offered by bibliometric data to produce indicators of scientific mobility. Large bibliographic datasets of disambiguated authors and their affiliations allow for the possibility of tracking the affiliation changes of scientists. Using the Web of Science as data source, we analyze the distribution of types of mobile scientists for a selection of countries. We explore the possibility of creating profiles of international mobility at the country level, and discuss potential interpretations and caveats. Five countries - Canada, The Netherlands, South Africa, Spain, and the United States- are used as examples. These profiles enable us to characterize these countries in terms of their strongest links with other countries. This type of analysis reveals circulation among and between countries with strong policy implications.
\end{abstract}

\title{
Keywords
}

Scientific mobility; Bibliometric indicators; International mobility; Internationalization; Research policy; Web of Science.

\section{Resumen}

Este trabajo presenta y describe las oportunidades metodológicas que ofrecen los datos bibliográficos para producir indicadores de movilidad científica. El uso de grandes conjuntos de datos bibliográficos con autores y afiliaciones desambiguadas, abre la posibilidad de rastrear cambios de afiliación de investigadores. Empleando la Web of Science como base de datos, desarrollamos distintas perspectivas para mostrar la movilidad observable de una selección de países. Exploramos la posibilidad de crear perfiles de movilidad internacional a nivel de países y discutimos cómo interpretar estos indicadores así como sus potenciales limitaciones. Para ello, estudiamos los casos de Canadá, Holanda, Sudáfrica, España y Estados Unidos. Sus perfiles permiten identificar a grupos de investigadores que muestran distintos tipos de movilidad, así como caracterizar los países con los que tienen mayores vínculos. Con este tipo de análisis se pueden hacer comparaciones entre países de origen y destino de cada país, especialmente relevantes en el contexto de política cientifica.

\section{Palabras clave}

Movilidad científica; Indicadores bibliométricos; Movilidad internacional; Internacionalización; Política científica; Web of Science.

Robinson-García, Nicolás; Sugimoto, Cassidy R.; Murray, Dakota; Yegros-Yegros, Alfredo; Larivière, Vincent; Costas, Rodrigo (2018). "Scientific mobility indicators in practice: International mobility profiles at the country level". El profesional de la información, v. 27, n. 3, pp. 511-520. 


\section{Introduction}

Mobility of scientists is a topic of great concern in the science policy arena. In recent decades mobility has become a key issue due to an ever-more globalized research landscape. While some countries rely on foreign-born scientists to maintain their scientific status (Levin; Stephen, 1999), other countries envision mobility as a way to improve their national scientific capacities (Ackers, 2008), or to integrate themselves into a perceived elite of scientifically advanced countries (Kato; Ando, 2017). These examples align closely with the concept of internationalization, understood as

'the policies and practices undertaken by academic systems and institutions -and even individuals- to cope with the global academic environment' (Altbach; Knight, 2007).

Therefore, many countries proactively implement policies to facilitate mobility of scientists (e.g., Ackers, 2005).

Until recently, bibliometrics has contributed very little to the study of scientific mobility. Existing scientific mobility indicators are often constructed using CV data, population statistics, or survey data (Laudel, 2003). These data sources provide data at different levels of analysis; some sources dictate aggregate-level analysis (e.g., national census) while others provide for individual-level analysis (e.g., CV data). Examples of studies on mobility using such data sources are those by Andújar, Cañibano and Fernández-Zubieta (2015) using CV data; Ackers (2005), based on interviews; Jonkers and Tijssen (2008), combining CV and bibliometric data; or Cruz-Castro and Sanz-Menéndez (2010) who use survey data, among others. While insightful, retrieving data from these sources is time consuming, resource intensive, and provides a fragmented picture of scientists' mobility flows, rather than a global overview of the phenomenon.

In recent decades mobility has become a key issue due to an ever-more globalized research landscape

It was Laudel (2003) who first suggested that affiliations found on scholarly papers could be employed as a more systematic way to track researchers' mobility by identifying institutional changes. At the time, such a task was still too time consuming (although maybe not as much as alternatives) as there was no direct link between the author's paper and their affiliation; hence, CV data and manual online searches were necessary to verify publications and identify information missing from bibliometric sources. Recent enhancement of bibliographic databases has eased this task significantly thanks to the introduction of author-affiliation linkages (from 2008 onwards in Web of Science). These new linkages are essential for the development of author name disambiguation algorithms, improving their capacity to identify the complete bibliographic output of individuals (Caron; Van-Eck, 2014; Smalheiser; Torvik, 2009).

The first attempt to track scientific mobility by bibliometric means was conducted by Moed, Aisati and Plume (2013). In this study and in their subsequent analyses (Halevi; Moed;
Bar-Ilan, 2016; Moed; Halevi, 2014), the authors explored the use of Scopus' Author ID (the disambiguated set of authors from Scopus) to track institutional changes of scientists across countries. In these studies, they established the feasibility of using bibliographic data to track mobility, and compare international collaboration indicators with mobility, productivity and scientific impact. These and similar studies addressed the assumption that scientific international mobility is beneficial to scientific systems (Wagner; Jonkers, 2017) and analyzed the phenomenon from a brain drain/ brain gain perspective. This perspective is often reflected in the terminology used to describe mobility. For instance, Moed and Halevi (2014) refer primarily to scientific migration, without considering other types of mobility. Similarly, Robinson-García et al. (2016) discuss return rates of outgoing scholars without mentioning other types of mobility or considering benefits from potential scientific collaboration ties between sending and receiving countries due to scientific mobility. These studies do not envision mobility as a brain circulation phenomenon.

Until recently, bibliometrics has contributed very little to the study of scientific mobility

Sugimoto, Robinson-García and Costas (2016) suggested that bibliometric analysis using a network perspective could more closely align with the brain circulation theory of the global scientific workforce. They linked countries with weights based on the number of shared scientific workers, defined as those scholars who had, at any given point in time, been affiliated to more than one country. Sugimoto et al. (2017) went beyond the network approach by establishing distinct patterns of scientific mobility, based on affiliation changes, and analyzing scientific impact between these patterns. They distinguished between 'migrants' and 'travelers' based on their affiliation path and the type of affiliation linkages they maintained (or did not maintain) with their 'country of origin', the country in which they first published. Based on these two mobility types, Sugimoto et al. (2017) determined that $72.7 \%$ of those bibliometrically-identified mobile scholars are travelers - people who are mobile but who never lose the affiliation country in which they published their first paper-.

More recently, Robinson-García et al. (2018) applied and expanded this taxonomy, developing four types of mobile scholars at the country level, distinguishing for each country those incoming migrants and travelers, along with outgoing migrants and travelers. In this study we delve into this typology, explaining how mobility indicators are built when based on bibliometric data and showcasing their potential use in research policy. We aim to describe in practical terms how this taxonomy can be useful when analyzing scientific mobility for a set of selected countries. As a proof-of-concept, we have purposively selected five countries with different types of migration profiles: Canada, The Netherlands, South Africa, Spain and the United States. This is considered an exploratory analysis to show the methodological and analytical possibilities of international mobility profiles of countries. 
The rest of the paper is structured as follows. First, we briefly describe our dataset. Then we explain how mobility indicators are constructed based on bibliographic data, pointing to caveats to interpretation and presenting our taxonomy of mobility indicators. Next, we develop the international mobility profile of five countries, namely: Canada, South Africa, Spain, The Netherlands, and United States. The aim of these profiles is not only to describe their scientific workforce in terms of international mobility, but also to identify with which countries they show the strongest ties.

\section{Data}

Our approach uses the CWTS in-house version of the Web of Science, which includes all publications indexed in the database since 1980 . We identify individuals by clustering publications based on the author name disambiguation algorithm developed by Caron and Van-Eck (2014). This algorithm uses a rule-based scoring system that links together documents that are likely authored by the same person by comparing bibliographic metadata of publications at four levels of analysis; author, article, publication and citation. When in doubt of a match, the algorithm is conservative and splits authors.

Based on this name disambiguation algorithm we define mobility events as changes in the country of affiliations within the output of each individual. As affiliation is one of the weighted fields, we expect the mobility changes found in our analyses to underrepresent total mobility. This approach may also fail to capture short-term mobility, such as temporary stays or research visits, when these events are not often recorded as affiliations on a resulting publication. For each individual and for a given year, we identified their affiliation type, differentiating between co-affiliated scholars (affiliated to more than one country in a single publication) and single affiliations (affiliated with only one country in a single publication). Furthermore, we distinguished between their country of origin and receiving countries. We assume that an individual's country of origin is that country in which they published their first paper (Robinson-García et al., 2016) while their receiving countries are any country with which the scholar held a subsequent affiliation (Sugimoto et al., 2017).

\section{Building scientific mobility indicators based on bibliographic data}

Full details of our taxonomy of mobility types are provided elsewhere (Sugimoto et al., 2017; Robinson-García et al., 2018). In this section we will offer a basic explanation on how we track mobility through publications and define the mobility types we developed. The first thing to note in this regard is that publication data offers only a proxy of mobility and does not necessarily track physical movements. Hence, scholars can be linked to one or more countries at the same time, which results in a multiplicative effect. Another caveat of this approach is that our capability to reliably identify mobile scholars is dependent on the visible productivity of these scholars in terms of their publications. This requirement has two direct consequences: on the one hand, we underrepresent mobility of scholars with small numbers of publications; on the other hand, publication delays and years with no publications represent holes in our data that may hinder trend analyses.

Figure 1 shows the number of affiliations by year for the top 25 countries with the largest share of mobile scholars who

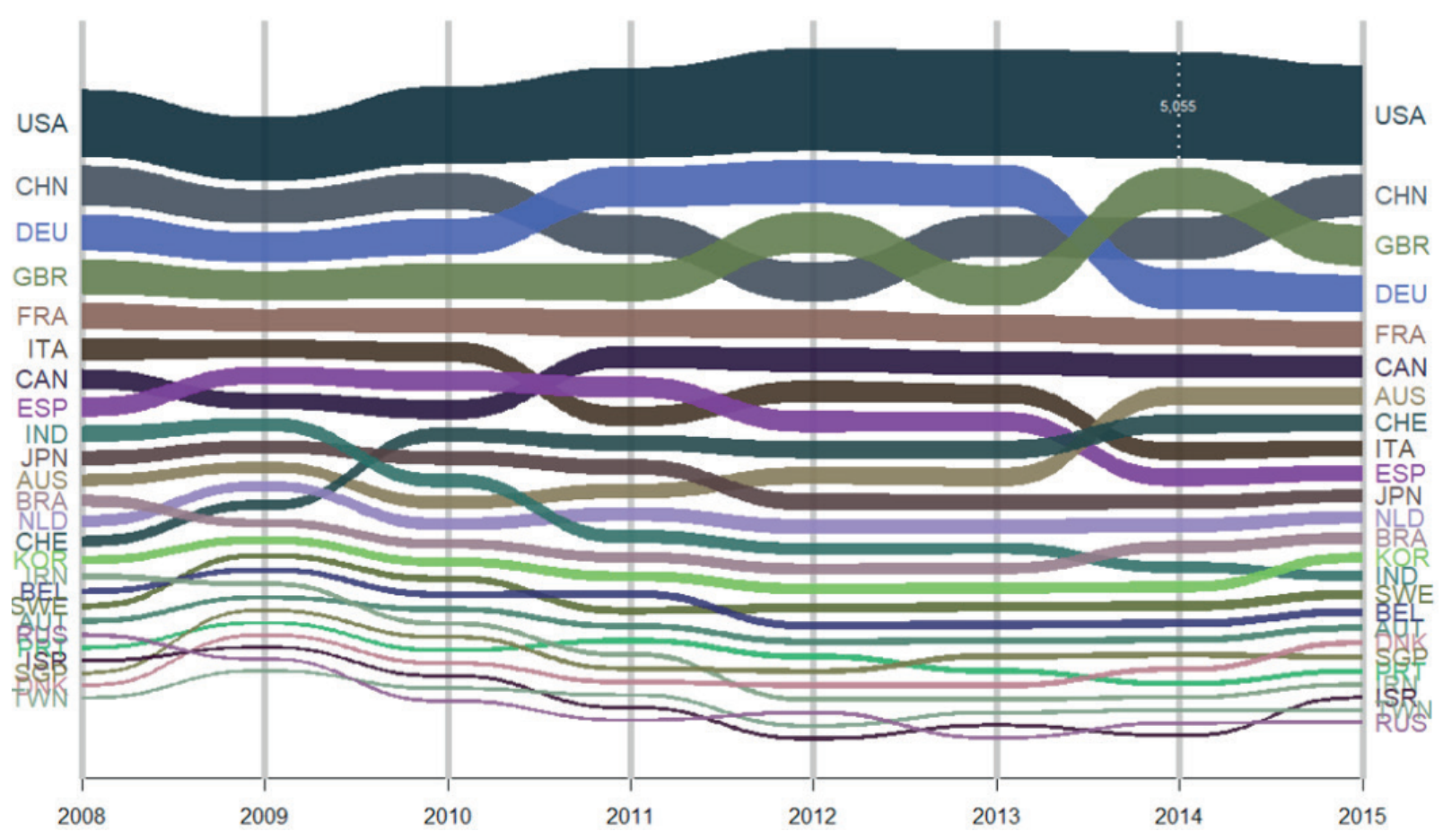

Figure 1. Trend analysis of number of affiliations for scholars publishing in Web of Science for the top 25 countries with the largest share of mobile scholars. Only scholars whose first publication year is 2008 and with at least 8 publications within the 2008-2015 period are included. ISO $3166-1$ alpha-3 codes are used to name countries. 
published the first paper in 2008 and who have published at least 8 papers within the 2008-2015 period. One of the problems with this type of analyses is dealing with blank years (years where a given scholars has produced no publications). One way of overcoming this limitation is to assume that no change takes place, and to assign to those empty years the country to which the scholar was last affiliated. Despite such issues, this approach provides insights, showing the dynamics of the scientific workforce of countries over time. For instance, we observe a decreasing number of mobile scientists in Italy, Spain, India and Russia. Similarly, we observe increases of internationally mobile scientific workforce in the United States, Australia and Switzerland.

We describe a typology of mobility indicators built on bibliometric data and showcase their potential use in research policy

Changes in the number of affiliations by country may result from scientists leaving one country and going to another, or because of scientists co-affiliating with a second or third country as well as their country of origin. Hence, some countries might see increases in the number of affiliations or the size of their workforce by recruiting scholars from elsewhere, while other countries may simply be sharing scholars with others. These two perspectives suggest that the phenomenon of scientific mobility is conceptually more closely related with a brain circulation framework (Sugimoto; Robinson-García; Costas, 2017) rather than with the more reductionist brain drain/brain gain model. A circulation model obliges us to distinguish between different types of mobile scholars. Here we use the taxonomy presented by Robinson-García et al. (2018) which defines four mobility types; at the country level, this taxonomy can be expanded to six types. For a complete description of the taxonomy we refer to the original paper. Figure 2 overviews the main differences between the four basic mobility types which we define as:

a) Not mobile. These are scholars who have affiliation/s in a single country in all their publications. They represent $96.3 \%$ of the scholars in the 2008-2015 period (Robinson-García et al., 2018). This large share of apparent non-mobile scholars can be explained by the strong skewness in scientific productivity, with extremely large shares of scholars only authoring a few papers (Ruiz-Castillo; Costas, 2014).

b) Migrants. These are scholars who, for at least one year, did not list the affiliation corresponding to their country of origin. They represent $1.0 \%$ of all scholars and $27.3 \%$ of mobile scholars in the $2008-2015$ period (Robinson-García et al., 2018). At the country level, these scholars can be further characterized as:

- Emigrants. Defined for country A as those who have country $A$ as their country of origin and at any given time they cease being affiliated to it.

- Immigrants. Defined for country A as those who have country $B$ as their country of origin and at any given time are affiliated to country $A$.

c) Travelers. Defined as scholars who at some point are affiliated to more than one country, but who in all years produce at least one publication still affiliated to their country of origin. They represent $1.3 \%$ of all scholars and $35.9 \%$ of mobile scholars in the $2008-2015$ period. At the country level, these scholars can be further characterized as:

- Outgoing travelers. Defined for country A as those who have country $A$ as their country of origin and at any time they are also affiliated to country $B$ while retaining their affiliation to country $A$.

- Incoming travelers. Defined for country A as those who have country $B$ as their country of origin and at any time they are also affiliated to country $A$ while retaining their affiliation to country $B$.

d) Non-directionals. Scholars who are affiliated in their first publication year to more than one country (they have more than one country of origin) and always show linkages between the same countries, hence precluding identifying directionality of changes. They represent $1.4 \%$ of all scholars and $36.8 \%$ of mobile scholars in the 2008-2015 period.

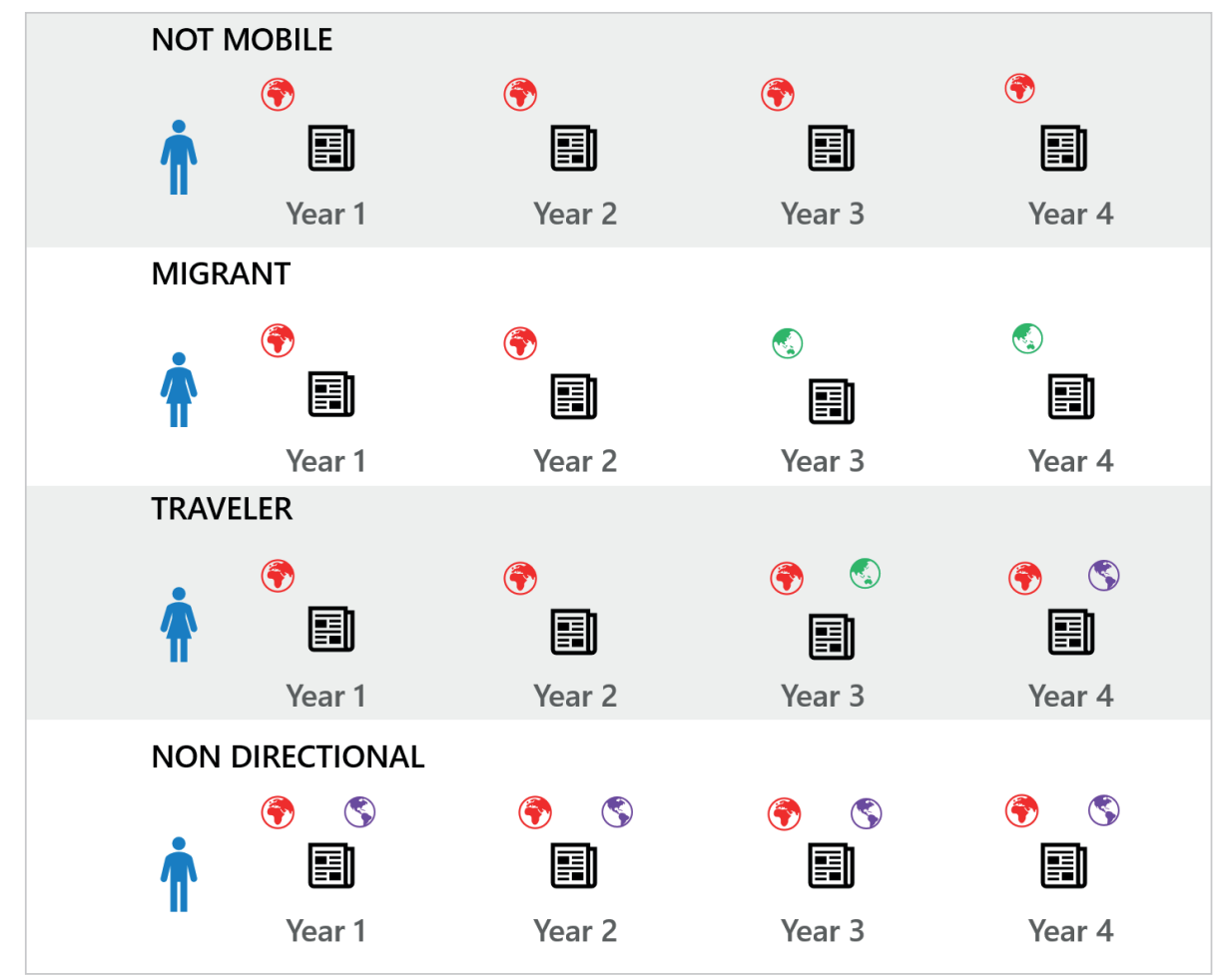

Figure 2. Overview of mobility types based on their affiliation changes. Red (Europe/Africa), green (Asia/ Oceania), blue (America), to indicate variations in countries. 


\section{The international mobility profiles of selected countries}

This mobility taxonomy allows us to develop indicators at the country level, such as a country's share of mobile scientists, migrants, or travelers (Robinson-García et al., 2018). In addition, citation impact or collaboration indicators can be calculated and compared for each distinct mobility population. Moreover, countries can be characterized and profiled based on their mobile scientific workforce.

Table 1 presents an overview of the internationally mobile scientific workforce of the five selected countries. As expected, the United States shows the largest overall number of scientists. Following the U.S. are Canada, Spain, The Netherlands and, lastly, South Africa. The United States shows the lowest share of mobile scientists $(6.8 \%)$ while The Netherlands $(16.7 \%)$ has the largest share, followed by South Africa (15.0\%). Considering only mobile scientists, the non-directionals are the most common type, accounting for, at the high end, $36.5 \%$ of all mobile scholars in the United States to a low of $25.5 \%$ in Spain. This group of scholars is the most difficult to explain as it is mostly formed by scientists with a single publication in which they are co-affiliated to more than one country. As suggested elsewhere (Robinson-García et al., 2018), a portion of those identified as non-directionals may also be publications for which the algorithm did not cluster with the actual author. The second largest type of mobile scientists are travelers, ranging from $43.2 \%$ of all mobile scholars in Spain to $35.9 \%$ in the United States. Migrants are the least common type of mobile scholar, ranging between $34.1 \%$ of mobile scholars in Canada to $26.0 \%$ in South Africa.

We observe larger differences between these countries when comparing shares of incoming scholars (immigrants and incoming travelers) and outgoing scientists (emigrants and outgoing travelers). For this analysis, we omit non-directional scholars, as it is not possible to discern their directionality of movement. We find that $41.2 \%$ of mobile scientists in Spain are outgoing while $33.3 \%$ are incoming. At the other end of the spectrum we find South Africa, where $24.9 \%$ of their mobile scientists are outgoing while $43.8 \%$ are incoming scholars. In this regard, we observe that Spain is the only country with more outgoing scholars than incoming, while the rest show greater shares for incoming scholars.

Figure 3 shows the relation between mobility types and the directionality of scholars. Except for Canada, there is a larger share of outgoing travelers, those who acquire new links with other countries, than emigrants for each analyzed country. A similar trend is observed for incoming scholars,

\section{Outgoing scientists}

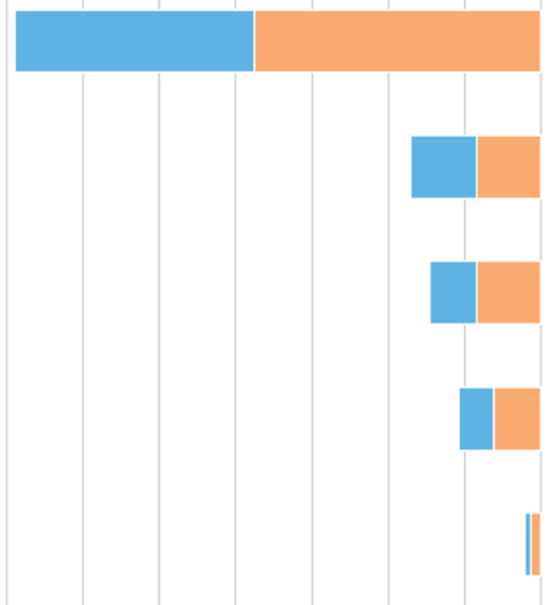

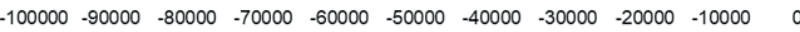
- Trained travelers $=$ Emigrants

\section{Incoming scientists}

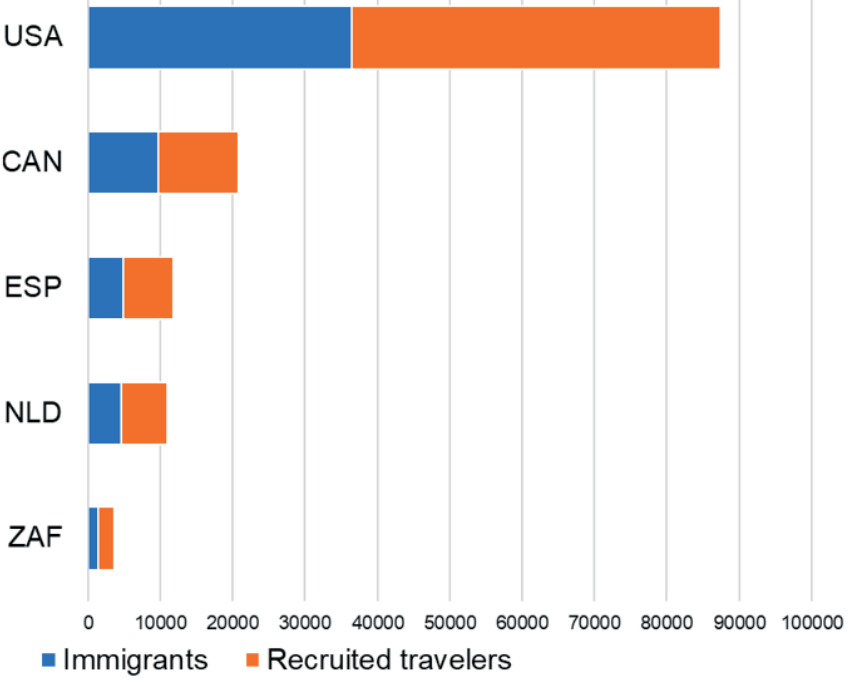

Figure 3. Total number of mobile scientists (excluding non-directionals) for Canada, Netherlands, South Africa, Spain and United States in the $2008-2015$ period 


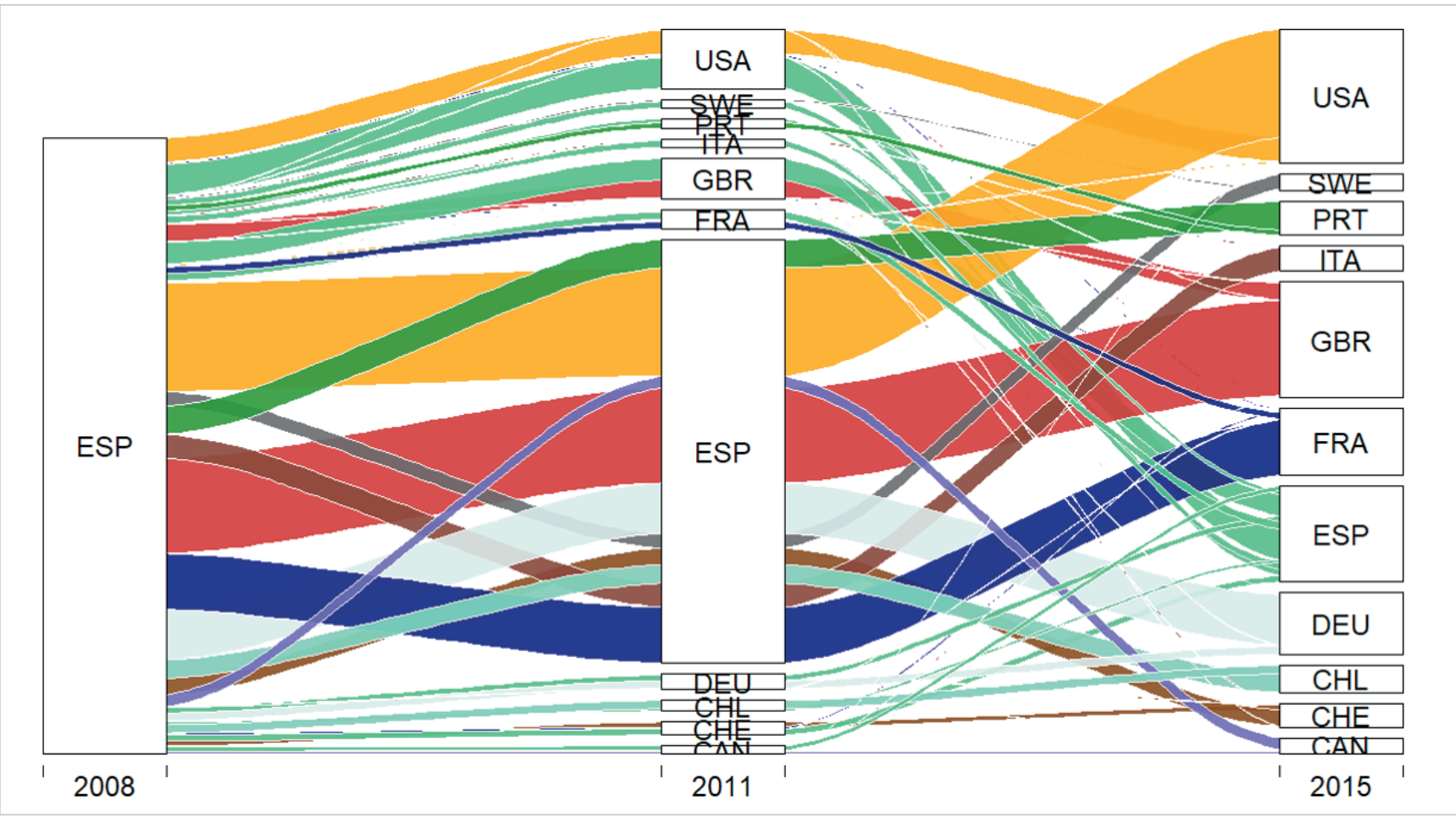

Figure 4. Flows of outgoing scholars from Spain. Only those who published their first paper in 2008 in Spain are included. Only the top 10 destinations are included.

where for every country there is a greater share of incoming travelers than there are immigrants.

In addition to analyzing the distribution of mobile scientists by country, we can also examine the source and destination countries of these mobile scholars. Figure 4 shows the flow of outgoing scholars originating in Spain in 2008, while figure 5 shows the flow of incoming scholars who eventually affiliate with Spain in 2015, starting from the top ten origin countries in 2008 . These alluvial figures can be used to show the movements of scholars across countries and over time; still, there are many issues that must be considered when interpreting these figures. First, only a fixed set of scholars can be analyzed. Hence, we showcase only those scholars who started publishing in 2008 and ignore the population dynamics resulting from scholars entering and exiting the publishing system. Furthermore, these figures include all types of mobile scholars, which is problematic because, as discussed previously, co-affiliations have a multiplicative effect whereby one person can count towards multiple countries. Co-affiliation affects mostly (but not exclusively) travelers and non-directionals. To solve this issue, we use fractional counting of scholars by country and year -in other words, scholars are fractionalized by the countries with which they were affiliated during the relevant time period-.

Most of the top 10 destinations of Spanish scholars are European countries (Figure 4) except for the United States, Chile and Canada. Using year of first publication as a proxy for age (Nane; Larivière; Costas, 2017), we can see that many outgoing scholars are young, and are thus likely to move to a different country after their third year of academic life, which may account for the lower share of Spanish affiliations in 2015. The top three destinations for scholars originating in Spanish are the United Kingdom, United States, and France. In the case of incoming scholars (Figure 5), we observe that the largest share are actually returned scholars, originating in Spain in 2008, becoming internationally mobile, and returning to Spain in 2015. Scholars from the United States and United Kingdom comprise the next largest shares of incoming scholars.

\section{Migrants represent $1.0 \%$ of all scholars} and $27.3 \%$ of mobile scholars in the 2008-2015 period

Whereas these alluvial visualizations give a quick overview of the flows and changes of the scholarly workforce over time, the analysis by mobility types provides a deeper understanding of a nation's mobility. Analysis of national mobility type distributions, when coupled with contextual information, can also reveal trends and directional flows which are hidden from the alluvial charts. Figure 6 shows the international mobility profile of the five analyzed countries. For Spain, we show the top countries with which most scholars are linked to, by mobility type. For the rest of the countries we show only the distributions for migrants. There are several countries that are both prominent sources of incoming and destinations for outgoing scholars and that are common between all five of our cases: these are the United Kingdom, the United States, Germany, and France. However, we do observe strong differences between each of the selected country's mobility distributions.

For instance, countries from the south of Europe such as Italy or Portugal, along with South American countries (i.e., Brazil, Mexico) are within the top countries sharing mobi- 
le scholars with Spain. However the outgoing distribution tends to include northern European countries such as Sweden or others like Australia as preferred destinations, rather than the southern European and South American countries common to incoming scholars.

In the case of Canada, we observe that United States is the preferred destination for most migrants, whereas the number of travelers is more distributed across other countries like the United Kingdom and Germany. We also observe the presence of Middle-East Asian countries like Iran and Saudi Arabia (only for emigrants), suggesting that these scholars could be receiving graduate training in Canada before returning to their home country. In the case of The Netherlands, there seems to be a more distributed share of scholars per country, although incoming scholars more often originate from southern European countries. The United States shows strong linkages with China, Germany, the United Kingdom, and with its neighbor Canada. Finally, in the case of South Africa, it is notable that while intra-continental migration is readily found in top positions, the United States and United Kingdom are the most preferred destinations and origins of migrants.

\section{Concluding remarks}

This paper presents and describes a methodological approach to develop scientific mobility indicators based on bibliometric data. It delves into the possibility of using affiliation data from publications to track international scientific exchanges. We discuss the strengths and limitations of this approach and further describe a taxonomy of mobility types, which then can be used to create mobility profiles of countries. To this end, we have profiled the five countries to which the authors of this paper are or have been affiliated. We compare these profiles and observe promi- nent similarities and differences between each country's mobile scholarly workforce. Their profiles suggest that there is a selected group or 'elite' of countries -namely United States, Germany, United Kingdom and France-, to which most of the selected countries are linked through mobility ties (Figure 6); this was already noted by Sugimoto et al. $(2016 ; 2017)$.

\section{We find that $41.2 \%$ of mobile scientists in Spain are outgoing while $33.3 \%$ are incoming}

It is important to highlight that the analytical approaches presented here are applicable to any country, and are possible to apply using any bibliographic database in which author-affiliation linkages are available and complete. Moreover, these methods can also be applied to any set of scholars; one example is analysis of a selection of countries, as done in this paper, but this same approach can also be used for any selection of regions, cities, or even institutions. It would even be possible to study the institutional mobility profile of the scholars affiliated with a given set of universities. Thus, the type of analysis that we introduce here is not restricted to countries, but is applicable to many different geographical and institutional entities. Future research will focus on these other more advanced and more granular scientific mobility profiles.

Scientific mobility indicators opens the door for analysis of global mobility trends and study of the evolution of the global scholarly workforce. At the same time, these indicators can provide a better understanding of the phenome-

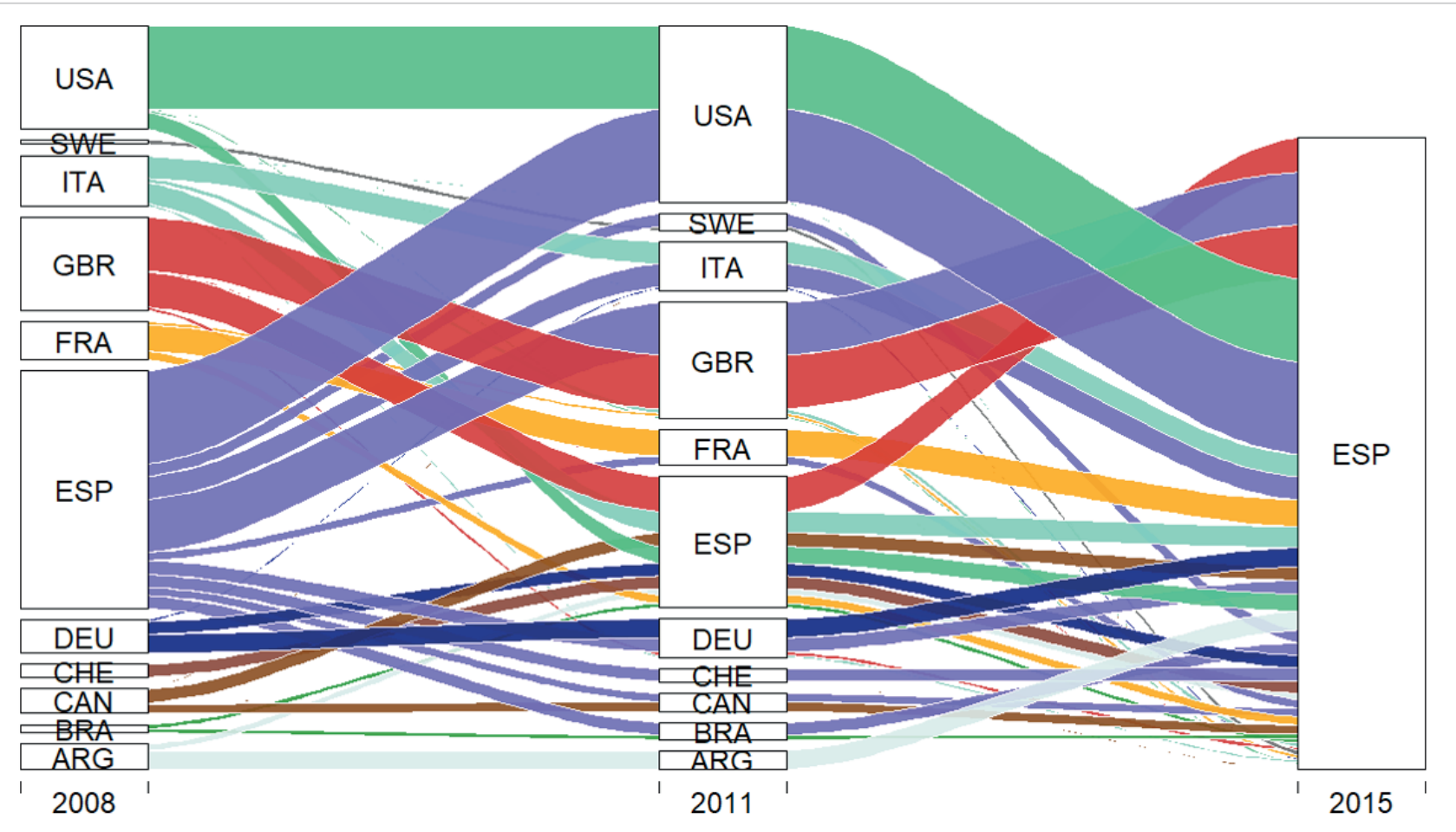

Figure 5. Flows of incoming scholars to Spain. Only those who published their first paper in 2008 and ended in 2015 in Spain are included. Only the top 10 countries of origin are included. 


\section{A) SPAIN}

Emigrating to

USA 1340

GBR 101

DEU 670

FRA 621

ITA 328

MEX 289

CHE 288

PRT 234

CHL 223

BRA 219

NLD 219

CAN 206

SWE 183

BEL 165

AUS 162

B) CANADA

\begin{tabular}{|c|c|}
\hline Emigrating to & Immigrating fre \\
\hline USA 4055 & USA 3372 \\
\hline GBR 946 & GBR 966 \\
\hline AUS 511 & FRA 780 \\
\hline DEU 495 & DEU 509 \\
\hline FRA 477 & IRN 414 \\
\hline $\mathrm{CHN} 393$ & AUS 351 \\
\hline CHE 252 & CHN 339 \\
\hline SAU 227 & IND 280 \\
\hline JPN 196 & CHE 231 \\
\hline NLD 168 & JPN 220 \\
\hline IND 136 & ITA 212 \\
\hline SWE 127 & ESP 206 \\
\hline ESP 118 & BRA 199 \\
\hline ITA 110 & NLD 190 \\
\hline IRN 108 | & || ISR 123 \\
\hline
\end{tabular}

\section{D) UNITED STATES}

Emigrating to

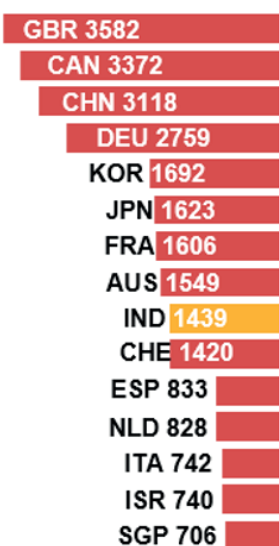

Immigrating from

\begin{tabular}{|c|}
\hline CAN 4055 \\
\hline GBR 3995 \\
\hline DEU 3211 \\
\hline CHN 2627 \\
\hline FRA 2249 \\
\hline JPN 1779 \\
\hline IND 1706 \\
\hline ITA 1554 \\
\hline ESP 1340 \\
\hline CHE 1226 \\
\hline AUS 1142 \\
KOR 1024 \\
NLD 985 \\
BRA 984 \\
ISR 891 \\
\hline
\end{tabular}

Traveling to

USA 1890

GBR 126

FRA 840

DEU 702

ITA 592

NLD 351

PRT 349

BRA 316

CHE 315

SWE 265

CAN 249

BEL 238

CHL 233

MEX 225

AUS 181

\section{C) NETHERLANDS}

Emigrating to

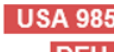

DEU 802

GBR 752

BEL 320

CHE 286

FRA 279

AUS 230

ESP 208

CAN -190

SWE -166

ITA - 137

CHN -109

NOR -102

DNK -94

AUT -66

Immigrating from

E) SOUTH AFRICA

Emigrating to Immigrating from

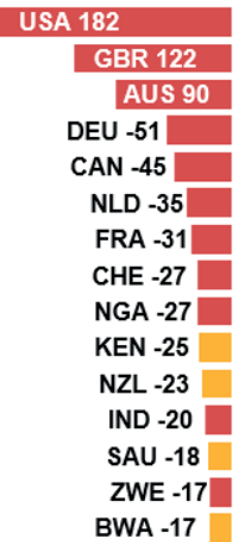

\begin{tabular}{|l|}
\hline \multicolumn{1}{|c|}{ GBR 228} \\
\hline \multicolumn{2}{|c|}{ USA 203 } \\
\hline IND 118 \\
\hline FRA 85 \\
\hline DEU 79 \\
NGA 69 \\
CAN 54 \\
AUS 53 \\
NLD 41 \\
ZWE 40 \\
ITA 39 \\
CHE 28 \\
CHN 27 \\
ESP 23 \\
BEL 21
\end{tabular}

Figure 6. Scientific international mobility at the country level for A), B) Spain, C) Canada, D) Netherlands, E) United States and F) South Africa. Only for Spain migrants (A) and travelers (B) are shown, for the rest only migrants are included. Countries in yellow appear only in one of the top 15 list of linked countries to the analyzed one.

non of international collaboration (Chinchilla-Rodríguez et al., 2017). Moreover, because they are built on bibliometric data, mobility indicators can easily be combined with citation impact indicators (Sugimoto et al., 2017), allowing the possibility for further developments and a more nuanced understanding of mobility. However, these indicators are not free of caveats and limitations, which must be consi- dered both, when constructing and interpreting them. Our distinction between migrants and travelers can contribute to the ongoing discussion on mobility, as it reflects the complexity of the phenomenon. The distinction also goes beyond the common perception of scholarly mobility in science as a physical act or a permanent move. The fact that scholars may be contributing to more than one institution/ 
country with their publications reveals that the current research context allows them to establish ties with different countries beyond physical mobility. Further research should focus on expanding the theoretical interpretation of such indicators to provide more advanced research policy discussions around mobility.

\section{References}

Ackers, Louise (2005). "Moving people and knowledge: Scientific mobility in the European Union". International migration, v. 43, n. 5, pp. 99-131.

https://doi.org/10.1111/j.1468-2435.2005.00343.x

Ackers, Louise (2008). "Internationalisation, mobility and metrics: A new form of indirect discrimination". Minerva, v. 46, n. 4, pp. 411-435.

https://doi.org/10.1007/s11024-008-9110-2

Altbach, Philip G.; Knight, Jane (2007). "The internationalization of higher education: Motivations and realities". Journal of studies in international education, v. 11, n. 3-4, pp. 290-305.

https://doi.org/10.1177/1028315307303542

Andújar, Inés; Cañibano, Carolina; Fernández-Zubieta, Ana (2015). "International stays abroad, collaborations and the return of Spanish researchers". Science, technology and society, v. 20, n. 3, pp. 322-348.

https://doi.org/10.1177/0971721815597138

Caron, Emiel; Van-Eck, Nees-Jan (2014). “Large scale author name disambiguation algorithm using rule-based scoring and clustering". In: $19^{\text {th }} \mathrm{Inl}$ conf on science and technology indicators. Context counts: Pathways to master big data and little data" CWTS-Leiden University, pp. 79-86.

Chinchilla-Rodríguez, Zaida; Miao, Lili; Murray, Dakota; Robinson-García, Nicolás; Costas, Rodrigo; Sugimoto, Cassidy R. (2017). "Networks of international collaboration and mobility: A comparative study". In: $16^{\text {th }}$ Intl conf on scientometrics \& informetrics.

https://goo.gl/5jnHKG

Cruz-Castro, Laura; Sanz-Menéndez, Luis (2010). “Mobility versus job stability: Assessing tenure and productivity outcomes". Research policy, v. 39, n. 1, pp. 27-38. https://doi.org/10.1016/j.respol.2009.11.008

Halevi, Gali; Moed, Henk F.; Bar-Ilan, Judit (2016). "Does research mobility have an effect on productivity and impact?". International higher education, v. 86, pp. 5-6.

https://doi.org/10.6017/ihe.2016.86.9360

Jonkers, Koen; Tijssen, Robert (2008). “Chinese researchers returning home: Impacts of international mobility on research collaboration and scientific productivity". Scientometrics, v. 77, n. 2, pp. 309-333.

https://doi.org/10.1007/s11192-007-1971-x

Kato, Maki; Ando, Asao (2017). "National ties of international scientific collaboration and research mobility found in Nature and Science". Scientometrics, v. 110, n. 2, pp. 673694.

http://doi.org/10.1007/s11192-016-2183-z
Laudel, Grit (2003). "Studying the brain drain: Can bibliometric methods help?" Scientometrics, v. 57, n. 2, pp. 215-237. https://goo.gl/cS9pTy

https://doi.org/10.1023/A:1024137718393

Levin, Sharon G.; Stephen, Paula E. (1999). "Are the foreign born a source of strength for U.S. science?". Science, v. 285, n. 5431, pp. 1213-1214.

https://doi.org/10.1126/science.285.5431.1213

Moed, Henk F.; Aisati, M’hamed; Plume, Andrew (2013). "Studying scientific migration in Scopus". Scientometrics, v. 94, n. 3, pp. 929-942. https://doi.org/10.1007/s11192-012-0783-9

Moed, Henk F.; Halevi, Gali (2014). "A bibliometric approach to tracking international scientific migration". Scientometrics, v. 101, n. 3, pp. 1987-2001. https://doi.org/10.1007/s11192-014-1307-6

Nane, Gabriela F.; Larivière, Vincent; Costas, Rodrigo (2017). "Predicting the age of researchers using bibliometric data". Journal of informetrics, v. 11, n. 3, pp. 713-729. https://doi.org/10.1016/j.joi.2017.05.002

Robinson-García, Nicolás; Cañibano, Carolina; Woolley, Richard; Costas, Rodrigo (2016). "Scientific mobility of early career researchers in Spain and The Netherlands through their publications". In: $21^{\text {st }}$ Int l conf on science and technology. "Peripheries, frontiers and beyond". Ingenio (CSIC-UPV), Universitat Politècnica de València, Spain.

https://arxiv.org/abs/1606.00155

Robinson-García, Nicolás; Sugimoto, Cassidy R.; Murray, Dakota S.; Yegros-Yegros, Alfredo; Larivière, Vincent; Costas, Rodrigo (submitted). "The many faces of mobility: Using bibliometric data to track scientific exchanges".

https://arxiv.org/abs/1803.03449

Ruiz-Castillo, Javier; Costas, Rodrigo (2014). "The skewness of scientific productivity". Journal of informetrics, v. 8, n. 4, pp. 917-934.

https://doi.org/10.1016/j.joi.2014.09.006

Smalheiser, Neil R.; Torvik, Vetle I. (2009). "Author name disambiguation". Annual review of information science and technology, v. 43, pp. 1-43.

https://doi.org/10.1002/aris.2009.1440430113

Sugimoto, Cassidy R.; Robinson-García, Nicolás; Costas, Rodrigo (2016). "Towards a global scientific brain: Indicators of researcher mobility using co-affiliation data". OECD Blue Sky III Forum on Science and Innovation Indicators, Ghent, September 19-21.

https://arxiv.org/abs/1609.06499

Sugimoto, Cassidy R.; Robinson-García, Nicolás; Murray, Dakota S.; Yegros-Yegros, Alfredo; Costas, Rodrigo; Larivière, Vincent (2017). "Scientists have most impact when they're free to move". Nature, v. 550, n. 7674, pp. 29-31. http://doi.org/10.1038/550029a

Wagner, Caroline S.; Jonkers, Koen (2017). “Open countries have strong science". Nature, v. 550, n. 7674, pp. 32-33.

https://doi.org/10.1038/550032a 